\title{
Spububaúde
}

\section{O papel do sistema imunológico na patogênese da doença periodontal}

\author{
The role of the immune system in the pathogenesis of periodontal disease
}

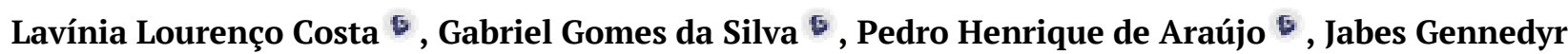 \\ da Cruz Lima ${ }^{\circ}$, Glória Maria de França ${ }^{\circ}$, Juliana Campos Pinheiro ${ }^{\circ}$
}

Universidade Federal do Rio Grande do Norte. Centro de Biociências. Natal, Rio Grande do Norte, Brasil. *Autor para correspondência. E-mail: julianapinheiroodonto92@gmail.com

\begin{abstract}
Resumo: Introdução: A doença periodontal é caracterizada por um distúrbio da microbiota presente no ambiente bucal, ocasionando uma resposta imunológica no individuo, desta forma, afetando os tecidos de proteção e apoio do periodonto. Portanto, o presente artigo objetiva-se a elucidar o papel do sistema imunológico na patogênese da doença periodontal. Revisão: O sistema imunológico utiliza mecanismos específicos promovidos por células, como os linfócitos, macrofágos, monócitos, mastócitos e neutrófilos, assim como, os mecanismos associados a moléculas especificas, caracterizadas como as citocinas antiinflamatórias e pró-inflamatórias, prostaglandinas, inibidores de proteinases e metaloproteinases (MMPs), que em conjunto, estando presentes na fase ativa da doença periodontal polimicrobiana. A progressão das doenças do periodonto são induzidas por um processo inflamatório que gradualmente leva à sua destruição, ocasionando a perda dentária. A resposta imunológica inata participa ativamente do desenvolvimento da doença periodontal e a resposta imunológica adquirida está relacionada a progressão da doença e destruição do osso alveolar. Por outro lado, a resposta imunológica humoral mostra-se relacionada a proteção dos tecidos periodontais, tendo resultados positivos. Considerações finais: As MMPs, TNF-alfa, RANKL e IL-1 têm sido relatadas como uma ferramenta eficaz para o diagnóstico da doença. Embora exista um amplo conhecimento a respeito da patogênese das doenças periodontais inflamatórias, outros estudos ainda precisam ser realizados para um melhor conhecimento sobre os eventos celulares e moleculares envolvidos nesta patologia.
\end{abstract}

Palavras-chave: doenças periodontais, imunidade inata, imunidade adaptativa.

\begin{abstract}
Introduction: Periodontal disease is characterized by a disturbance of the microbiota present in the oral environment, causing an immune response in the individual, thus affecting the protection and support tissues of the periodontium. Therefore, this article aims to elucidate the role of the immune system in the pathogenesis of periodontal disease. Review: The immune system uses specific mechanisms promoted by cells, such as lymphocytes, macrophages, monocytes, mast cells and neutrophils, as well as mechanisms associated with specific molecules, characterized as anti-inflammatory and pro-inflammatory cytokines, prostaglandins, proteinase inhibitors and metalloproteinases (MMPs), which together, being present in the active phase of polymicrobial periodontal disease. The progression of periodontal diseases is induced by an inflammatory process that gradually leads to its destruction, causing tooth loss. The innate immune response actively participates in the development of periodontal disease and the acquired immune response is related to disease progression and destruction of the alveolar bone. On the other hand, the humoral immune response is shown to be related to the protection of periodontal tissues, with positive results. Final Remarks: MMPs, TNF-alpha, RANKL and IL-1 have been reported as an effective tool for diagnosing the disease. Although there is a wide knowledge about the pathogenesis of inflammatory periodontal diseases, other studies still need to be carried out to better understand the cellular and molecular events involved in this pathology.
\end{abstract}

Keywords: periodontal diseases, immunity innate, adaptative immunity.

\section{Introdução}

A doença periodontal é caracterizada por um distúrbio da microbiota presente no ambiente bucal, ocasionando uma resposta imunológica no individuo, desta forma, afetando os tecidos de proteção e apoio do periodonto, podendo ocasionar a perda dentária, caso não seja tratada (Ebersole et al., 2016). O sistema imunológico utiliza mecanismos moleculares específicos cordenados por células, como os linfócitos, macrofágos, monócitos, mastócitos e neutrófilos, e pelos mecanismos associados a moléculas especificas do 
sistema, sendo caracterizadas como citocinas anti e pró-inflamatórias, prostaglandinas, inibidores de proteinases e metaloproteinases da matriz (MMPs), que em conjunto, protegem o periodonto contra os patógenos. No entanto, o sistema imunológico, dependendo do tipo patógeno, pode apresentar dois tipos de respostas, dentre elas, destacam-se a resposta inata não específica e a resposta adaptativa específica, que por sua vez, é mais efetiva, especificamente moldada para os patógenos agressores (Kayal, 2013; Hasan et al., 2014).

A degradação do tecido periodontal ocorre de maneira gradual sendo induzida principalmente por enzimas liberadas por células do sistema imunológico durante o processo inflamatório (Ebersole et al., 2013). Essas enzimas endógenas desempenham um importante papel nos processos fisiológicos e patológicos, atuando na remodelação e degradação da matriz extracelular dos tecidos periodontais. Pacientes com inflamação periodontal apresentam elevadas concentrações de TNF-alfa, IL-1, RANKL e MMP-13, podendo indicar presença de periodontite (Rethman, 2010). No entanto, a presença de altos níveis de MMP-8 na saliva e fluido gengival pode estar também associada à gravidade da doença. Desta forma, mudanças na homeostase dessas enzimas estão diretamente envolvidas na degradação tecidual, assim como, em diferentes estágios da doença periodontal, podendo ser úteis para a compreensão da patogênese, diagnóstico e tratamento. (Alnaeeli et al., 2006). Sendo assim, o objetivo desta revisão de literatura foi abordar os aspectos da imunopatogênese da doença periodontal, enfatizando a papel da resposta imunólogica do hospedeiro.

\section{Revisão}

A doenças periodontais, são caracterizadas pela presença de inflamação acometendo o periodonto, sendo este, subdividido em periodonto de proteção, composto pelo tecido gengival e o periodonto de sustentação, dos quais fazem parte, o cemento, ligamento periodontal e osso alveolar. Dentre as causas da doença periodontal destacam-se, a ação do biofilme bacteriano e acúmulo de placa bacteriana mineralizada, colaborando desta forma, para a formação de bolsas periodontais (Alnaeeli et al., 2006). A doença periodontal é classificada de acordo com o seu estágio de acometimento e destruição dos tecidos periodontais, sendo classificada em gengivite, quando ocorre a inflamação do tecido gengival, sem afetar o periodonto de sustentação e periodontite, representando um estágio avançado da doença, sendo caracterizada pela perda de inserção do ligamento periodontal e a destruição dos tecidos ósseos adjacentes, podendo ocasionar a perda dentária (Ebersole et al., 2013). O entendimento da patogênese das doenças periodontais, enquanto doença de caráter infeccioso, vai além da elucidação das bactérias associadas ao biofilme supra e subgengival. A participação do sistema imunológico frente às agressões que os patógenos podem ocasionar aos tecidos de suporte dentários representa um importante fator, podendo causar uma alteração na homeostasia desses tecidos afetados (Correa \& Rengifo, 2013).

O sistema imunológico é composto por estruturas e processos biológicos que protegem o organismo humano contra doenças. De modo a funcionar corretamente, o sistema imunológico detecta uma grande variedade de agentes patogênicos e os distingui dos tecidos saudáveis. Entretanto, os agentes patogénicos podem rapidamente evoluir e adaptar-se ao hospedeiro, evitando a detecção e neutralização do sistema imunológico, em contraparte, vários mecanismos de defesa evoluíram no sentido de os reconhecer e neutralizar patógenos (Rethman, 2010). O sistema imunológico fornece proteção ao organismo através dos seus mecanismos de defesa específicos, porém, os patógenos podem penetrar nestas barreiras, desencadeando uma resposta imediata não específica. Na resposta inata os mecanismos efetores são ativados rapidamente, sendo esta a primeira linha de defesa do organismo. Entretanto, o patógeno pode evitar a resposta inata, e o sistema imunológico adquirido é ativado se adaptando a infecção de acordo com o tipo de patógeno. A imunidade adquirida, por sua vez, é uma resposta imunológica mais especifica, porém demorada, quando comparada com a imunidade inata, sendo subdividida em imunidade celular e humoral (Gibertoni et al., 2017). A imunidade adquirida é responsável, por conferir uma memória imunológica aos linfócitos T e B, permitindo a adaptação do organismo a determinados microrganismos externos. Os linfócitos T e B atuam na resposta imunológica das doenças periodontais, apresentando-se em elevadas concentrações (Luan et al., 2018).

Diversas células e moléculas estão associadas a resposta imunológica inata e adquirida, os leucócitos compreendem uma linha de defesa do sistema imunológico inato, podendo ser divididos em neutrófilos, eosinófilos, basófilos e mastócitos, monócitos, linfócitos, células NK e células dendríticas. As células associadas a resposta imunológica inata, são responsáveis por identificar e eliminar os micro-organismos ou células infectadas. Os mastócitos estão presentes em grandes quantidades nos tecidos periodontais inflamados, sugerindo uma possível participação destas células na patogenia da doença (Garlet, 2010). 
Quando os mastócitos são ativados por patógenos, há uma liberação de mediadores químicos, como as citocinas pró-inflamatórias e imunorreguladoras que ativam outras células, contribuindo, para o desenvolvimento e a amplificação da resposta de defesa do indivíduo. Além disso, sabe-se que os mastócitos possuem uma grande variedade de moléculas com potencial de mediar a destruição da matriz extracelular, sendo uma característica encontrada na doença periodontal inflamatória (Ebersole et al., 2016).

As células do sistema imunológico inato são também importantes mediadores relacionados na ativação do sistema imunológico adquirido (Hasan et al., 2014). Os linfócitos T são células efetoras da resposta mediada, enquanto que os anticorpos (imunoglobulinas) são os responsáveis pela criação da resposta humoral, também chamada de memória imunológica. Atualmente, são conhecidos três tipos de células T auxiliares, sendo caracterizadas como Th1, Th2 e Th3. As moléculas envolvidas nas células Th1, são a IL-2, IFN-g e TNF-b. Já nas células Th2, as citocinas geradas são a IL-4, IL-5, IL-6, IL-10, IL-13 e por fim, as células Th3 ou Th0 produzem o TGF-a, que está relacionado a respostas imunológicas da mucosa oral. A resposta imunológica humoral do hospedeiro, ocorre através da ação de citocinas, que determinarão a produção de diferentes classes de imunoglobulinas, atuando na função dos anticorpos. As subclasses proteicas das imunoglobulinas A e G podem ser produzidas no periodonto, sendo comumente encontradas no fluido crevicular e reagindo com diferentes lipossacarideos e carboidratos bacterianos no processo da doença periodontal (Isaza-Guzmán et al., 2016). Na doença periodontal, o envolvimento do sistema imunológico depende da severidade e progressão da doença, podendo ter a participação da resposta imunológica inata ou adquirida. As células da imunidade adquirida, apesar de protegerem o organismo contra os agentes infecciosos, podem produzir substâncias ocasionando efeitos negativos, provocando a reabsorção patológica do osso alveolar, que dependendo do estágio e controle da doença, pode ocorrer a perda dentária (Luan et al., 2018).

As bactérias que compõem o biofilme dentário presente apresentam um papel negativo em relação à perda óssea alveolar. As principais bactérias associadas são as Bacteroides gingivalis, Fusobacterium nucleatum, Actinobacillus actinomycetemcomitans, Prevotella intermédia, Tannerella forsythia, Treponema denticola e Porphyromonas gingivalis. O desequilíbrio na hemostasia das bactérias com a microbiota do periodonto, ocasionam uma sinalização para o sistema imunológico inato, neutrófilos e o sistema complemento, gerando desta forma, uma inflamação no local (Ebersole et al., 2013; Correa \& Rengifo, 2013). Os lipopolissacarídeos são componentes que estão presentes nas membranas externas das bactérias Gram-negativas e apresentam uma alta capacidade de desencadear respostas inflamatórias no hospedeiro, atuando como um mediador osteolítico, através da ativação de diferentes vias moleculares (Liu et al., 2010). Em condições normais, os osteoblastos secretam as citocinas chamadas de RANKL, que se ligam aos receptores RANK, expressos nos osteoclastos, induzindo a diferenciação, ativação e a sobrevivência dos osteoclastos. Para regular esse processo, os osteoblastos secretam a osteoprotegerina, que se por sua vez, se liga ao RANKL bloqueando a ligação com o RANK. Dessa maneira, para haver uma homeostase no tecido ósseo, é necessário haver um equilíbrio entre a secreção de RANKL e OPG. Na doença periodontal, ocorre um desequilíbrio entre essas citocinas, ocasionando uma produção maior de RANKL, ocasionando um aumento da reabsorção óssea, enquanto que a formação óssea ocorre de maneira insuficiente a essa proporção (Correa \& Rengifo, 2013). Dessa forma, a doença periodontal induz a perda de tecido ósseo alveolar, através de diversos mecanismos imunológicos resultando na perda do suporte dentário e, consequentemente na perda dos dentes (Morais et al., 2018).

\section{Discussão}

As doenças periodontais inflamatórias afetam os tecidos de suporte dos elementos dentários, sendo desencadeadas por microrganismos Gram-negativos anaeróbios e facultativos, também conhecidos como microrganismos periodontopatógenos, sendo que alguns destes possuem capacidade de invadir os tecidos, ocasionando infecção (Morais et al., 2018). Sabe-se que a evolução da doença periodontal é influenciada pela resposta imunológica do hospedeiro e envolve a participação de diversos tipos celulares, os quais produzem uma vasta gama de mediadores químicos, que atuam no local modulando a resposta de defesa em busca do controle da infecção. A periodontite é uma infecção polimicrobiana induzida por um processo inflamatório, que gradualmente ocasiona a destruição do periodonto (Bedi, Mahendra, \& Ambalavanan, 2015). De acordo com a literatura revisada, várias citocinas presentes nos fluidos orais têm sido propostos como possíveis biomarcadores imunológicos na doença periodontal, como as metaloproteinases, TNF-alfa e IL-1, indicando a progressão da doença. 
O sistema imunológico atua na defesa do hospedeiro, fazendo uso de diferentes respostas. Na imunidade inata, as células fagocitárias e efetoras são atraídas para o local da infecção através da ação de citocinas e outros mediadores inflamatórios. Este tipo de imunidade atua, como a primeira linha de defesa. Na imunidade adaptativa os linfócitos antígeno-específicos proliferam e se diferenciam em outros tipos celulares, eliminação efetivamente os patógenos. Esse processo gera uma grande quantidade de linfócitos com memória celular, protegendo o organismo contra reinfecções (Sima \& Glogauer, 2013). Na presente revisão de literatura, pode-se observar que a imunidade inata e adquirida apresentam importantes papeis na patogênese da doença periodontal, apresentando cada uma suas funções especificas frente a infecção por periodontopatógenos.

Yoshie et al. (1985) avaliaram a importância da resposta imunológica na evolução da doença periodontal em ratos atímicos, nos quais a progressão ocorria de forma mais intensa, devido a ausência do timo nos animais. Nesse estudo, a reconstituição imunológica com células tímicas ocasionou uma redução da destruição óssea alveolar, demonstrando que os linfócitos $\mathrm{T}$ apresentam funções imunorreguladoras importantes. Dessa forma, pode-se afirmar que as atividades reguladoras mediadas pelas células $\mathrm{T}$ atuam como elementos protetores na doença periodontal. Spindler et al. (1996) observaram em sua pesquisa, que os pacientes com doença periodontal apresentavam elevados níveis de anticorpos séricos específicos contra Bacteroides gingivalis, quando comparados com pacientes que apresentavam um tecido periodontal saudável, indicando que esses esses patógenos periodontais estimulam a imunidade humoral no indivíduo. Atualmente, sabe-se que a imunopatogênese da doença periodontal está relacionada a uma interação complexa entre os microrganismos subgengivais e a resposta imunológica do hospedeiro. Desta forma, sabe-se que a presença de alterações na microflora, assim como a persistência de bactérias, como o Actinobacillus actinomycetemcomitans, estão relacionadas ao aumento da produção de citocinas pró-inflamatórias, resultando em eventos que provocarão a destruição do tecido gengival, cemento, ligamento periodontal e osso alveolar, aumentando da gravidade da doença (Bedi et al., 2015).

\section{Considerações finais}

De acordo com a literatura revisada, foi concluído que a resposta imunológica inata participa ativamente do desenvolvimento da doença periodontal e que a resposta imunológica adquirida está relacionada a progressão da doença e destruição do osso alveolar. Por outro lado, a resposta imunológica humoral mostrase relacionada a proteção dos tecidos periodontais, tendo resultados positivos. As MMPs, TNF-alfa, RANKL e IL-1 têm sido relatadas como as principais citocinas envolvidas na doença periodontal, estando presentes em altos níveis na saliva e fluido crevicular, funcionando como uma ferramenta eficaz para o seu diagnóstico. Desta forma, entendendo os mecanismos imunológicos desencadeadores da doença periodontal e sua progressão, é provável que futuramente, possam ser desenvolvidas novas terapias imunológicas para auxiliarem no tratamento de pacientes que apresentem a doença periodontal. Embora exista um amplo conhecimento a respeito da patogênese das doenças periodontais inflamatórias, outros estudos ainda precisam ser realizados para um melhor conhecimento sobre os eventos celulares e moleculares envolvidos nesta patologia.

\section{Referências}

Alnaeeli, M., Penninger, J. M., \& Teng, Y. T. A. 2006. Immune interactions with CD4+ T cells promote the development of functional osteoclasts from murine CD11c+ dendritic cells. The Journal of Immunology, 177(5), 3314-3326.

Bedi, T., Mahendra, J., \& Ambalavanan, N. 2015. Defensins in periodontal health. Indian Journal of Dental Research, 26(4), 340.

Correa, S. M., \& Rengifo, A. C. 2013. Mecanismos moleculares implicados en la destrucción ósea en la periodontitis. Revisión de la literatura. Revista Clínica de Periodoncia, Implantología y Rehabilitación Oral, 6(3), 142-147.

Ebersole, J. L., Dawson III, D. R., Morford, L. A., Peyyala, R., Miller, C. S., \& Gonzaléz, O. A. 2013. Periodontal disease immunology:'double indemnity'in protecting the host. Periodontology 2000, 62(1), 163-202.

Ebersole, J. L., Graves, C. L., Gonzalez, O. A., Dawson III, D., Morford, L. A., Huja, P. E., ... \& Wallet, S. M. 2016. Aging, inflammation, immunity and periodontal disease. Periodontology 2000, 72(1), 54-75. 
Garlet, G. P. 2010. Destructive and protective roles of cytokines in periodontitis: a re-appraisal from host defense and tissue destruction viewpoints. Journal of Dental Research, 89(12), 1349-1363.

Gibertoni, F., Sommer, M. E. L., Esquisatto, M. A. M., Amaral, M. E. C. D., Oliveira, C. A. D., Andrade, T. A. M. D., ... \& Felonato, M. 2017. Evolution of periodontal disease: immune response and RANK/RANKL/OPG system. Brazilian Dental Journal, 28(6), 679-687.

Hasan, A., \& Palmer, R. M. 2014. A clinical guide to periodontology: Pathology of periodontal disease. British Dental Journal, 216(8), 457.

Isaza-Guzmán, D. M., Tobón-Arroyave, S. I., \& Martínez-Pabón, M. C. 2016. Inmunopatogénesis de la enfermedad periodontal y células Th17:¿ continúa la controversia?. Avances en Periodoncia e Implantología Oral, 28(3), 115-124.

Kayal, R. A. 2013. The role of osteoimmunology in periodontal disease. BioMed Research International, 2013, 639368.

Liu, Y. C. G., Lerner, U. H., \& Teng, Y. T. A. 2010. Cytokine responses against periodontal infection: protective and destructive roles. Periodontology 2000, 52(1), 163-206.

Luan, X., Zhou, X., Naqvi, A., Francis, M., Foyle, D., Nares, S., \& Diekwisch, T. G. 2018. MicroRNAs and immunity in periodontal health and disease. International Journal of Oral Science, 10(3), 1-14.

Morais, E. F., Dantas, A. N., Pinheiro, J. C., Leite, R. B., Barboza, C. A. G., de Vasconcelos Gurgel, B. C., \& Almeida Freitas, R. 2018. Matrix metalloproteinase-8 analysis in patients with periodontal disease with prediabetes or type 2 diabetes mellitus: A systematic review. Archives of Oral Biology, 87, 43-51.

Morais, E. F., Pinheiro, J. C., Leite, R. B., Santos, P. P. A., Barboza, C. A. G., \& Freitas, R. A. 2018. Matrix metalloproteinase-8 levels in periodontal disease patients: A systematic review. Journal of periodontal research, 53(2), 156-163.

Rethman, M. P. 2010. Inflammation in chronic periodontitis and significant systemic diseases. Journal of the California Dental AssociationJ, 38(4), 247-57.

Sima, C., \& Glogauer, M. 2013. Macrophage subsets and osteoimmunology: tuning of the immunological recognition and effector systems that maintain alveolar bone. Periodontology 2000, 63(1), 80-101.

Spindler, S. J., Thompson, J. J., Yukna, R. A., \& Costales, A. D. (1986). Juvenile Periodontitis: I. Demonstration of Local Immunoglobulin Synthesis. Journal of Periodontology, 57(5), 300-304.

Yoshie, H., Taubman, M. A., Ebersole, J. L., Smith, D. J., \& Olson, C. L. 1985. Periodontal bone loss and immune characteristics of congenitally athymic and thymus cell-reconstituted athymic rats. Infection and Immunity, 50(2), 403-408.

\section{Minicurrículo}

Lavínia Lourenço Costa. Graduanda em Odontologia pela Universidade Federal do Rio Grande do Norte.

Gabriel Gomes da Silva. Graduando em Odontologia pela Universidade Federal do Rio Grande do Norte.

Pedro Henrique de Araújo. Cirurgião-dentista, graduado pela Universidade Federal do Rio Grande do Norte.

Jabes Gennedyr da Cruz Lima. Cirurgião-dentista, graduado pela Universidade Federal do Rio Grande do Norte.

Glória Maria de França. Cirurgiã-dentista, graduada pela Universidade Federal de Alagoas. Mestre em Patologia Oral pela Universidade Federal do Rio Grande do Norte (UFRN); Doutorado em Ciências Odontológicas (andamento)- área de concentração: Patologia Oral- UFRN (2018-2022). 
Juliana Campos Pinheiro. Cirurgiã-Dentista graduada pela Universidade Tiradentes. Mestre em Patologia Oral pela Universidade Federal do Rio Grande do Norte (UFRN); Doutorado em Ciências Odontológicas (andamento)- área de concentração: Biologia Experimental- UFRN (2018-2022); Membro da Sociedade Brasileira de Estomatologia e Patologia Oral (2016-atualmente).

Como citar: Costa, L.L., Silva, G.G., Araújo, P.H., Lima, J.G.C., França, G.M., \& Pinheiro, J.C. 2020. O papel do sistema imunológico na patogênese da doença periodontal. Pubsaúde, 3, a038. DOI: https://dx.doi.org/10.31533/pubsaude3.a038

Recebido: 28 mai. 2020.

Revisado e aceito: 5 jun. 2020.

Conflito de interesse: os autores declaram, em relação aos produtos e companhias descritos nesse artigo, não ter interesses associativos, comerciais, de propriedade ou financeiros que representem conflito de interesse.

Licenciamento: Este artigo é publicado na modalidade Acesso Aberto sob a licença Creative Commons Atribuição 4.0 (CC-BY 4.0). 